\title{
THE SHUTTLE INDUCED BACKGROUND: GASEOUS CONSTITUENTS
}

\author{
G. R. Carignan* and E. R. Miller** \\ *Space Physics Research Laboratory, Department of Atmospheric and Oceanic \\ Science, The University of Michigan, Ann Arbor, MI 48109, U.S.A. \\ ** Code ES64, Building 4481, NASA/Marshall Space Flight Center, Huntsville, \\ AL 35812, U.S.A.
}

\section{INTRODUCTION}

Because space science was caused to depend heavily on the use of payloads attached to the shuttle, it was necessary to plan for operation of scientiflc instruments within its induced environment. The potential for excessive contamination was recognized early; specifications were written, goals were set and measurements to provide inflight validation were planned. Among the measurements to characterize the on orbit gaseous environment have been a mass spectrometer on the Induced Environment Contamination Monitor (IECM) /1/, a mass spectrometer provided by the Alr Force /2/, a mass spectrometer on the European SPAS satellite /3/, and an ion mass spectrometer on the Plasma Diagnostic Payload /4/. Each of these 1nstruments has made a contribution to the understanding of the shuttle gaseous environment and through their collective measurements a coarse characterization of the environment can be made. other scientific instruments not specifically intended for this purpose, particularly instruments on Space Labs 1 and 2, have also made observations that elucidate the gaseous environment.

It should be stated at the outset that the gaseous environment in the vicinity of the shuttle is highly variable. It is known to depend on surface temperatures and angle of attack both of which dependencies are tied to orbital geometry. The environment in the payload bay can be dominated by instrument outgassing so there is a payload dependence. The water vapor background, at least on the early shuttle flights, appears to be dependent on the pre-launch environment; if the shuttle was exposed to heavy rainfall on the launch pad, it desorbed slgnificantly more water on orbit. The shuttle RCS thrusters are significant sources of contamination and so the environment is dependent upon the number and type of thruster firings and on the orbital geometry during firlng. Thus there is no single specification that defines the gaseous environment; 1 t is variable and dynamic with large changes from flight to flight and during individual flights.

\section{DISCUSSION}

Contamination due to water was recognized as probably the greatest threat to scientific instruments emplaced on the shuttle so it is not surprising that each of the instruments cited give special attention to its measurement. Water vapor has strong absorption in the infrared and its condensate on instrument surfaces is long lived and can be highly deleterious. As an example, mass spectrometers intended for measurement of earth and planetary atmospheres are typically baked at $300 \mathrm{C}$ for 100 hours while being vacuum pumped to achieve backgrounds of acceptable levels.

The IECM mass spectrometer spent roughly half of its measuring time tuned to mass 18 to detect water. Water is a difficult molecule to measure with a mass spectrometer because of 1ts affinity for instrument surfaces. Small amounts of water are lost to surface sorption and undermeasured and large amounts leave a background that masks subsequent small changes in contaminant flux. Most of the measurements provided by the IECM were made with the instrument looking outward from the payload bay so the flux of contaminants into the instrument was primarily that due to single collision backscattering off the ambient atmosphere. The scattering cross sections of these $8-\mathrm{km} / \mathrm{sec}$ collisions are not well known, adding uncertainty to the IECM determination of all contaminants, including water.

The measurement of water vapor on STS-4 provides a good 11lustration of the nature of the environment and 1 ts measurement. Figure 1 plots the envelope of mass 18 counts/2 seconds over the duration of the light of STS-4. Several interesting and important features emerge. Water vapor, as measured by the IECM, decreases monotonically over the flight time of STS-4 by a factor of 30 ; this suggests that most of the water contaminant is absorbed on shuttle surfaces before launch and this launched water slowly desorbs during the time in orbit. $A$ 
more detalled look at the water vapor shows that the desorption rate is temperature dependent. On the same flight Narcissi et a1 /2/ show a striking correlation between mass 18 detector current and sensor temperature which they further correlate with payload bay temperature. This instrument was oriented such that its field-of-view included large surface areas of the payload bay. This arrangement essentially precludes the determination of column densities of contaminants but it does greatly increase sensitivity for the direct measurement of fluxes from the surfaces.

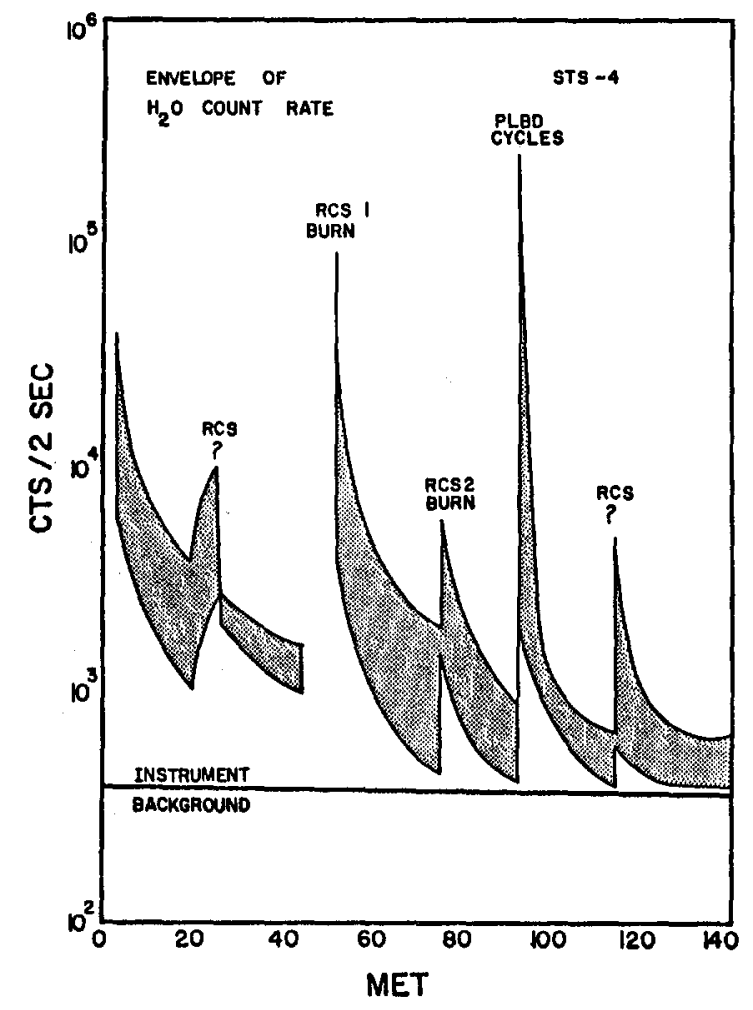

Fig. 1. The envelope of maximum and minumum values of the count at mass 18 per two seconds over the duration of the flight of STS -4 .

The extrema of the envelope of mass 18 counts are largely a consequence of angle of attack of the shuttle. The interpretation is that a more or less constant flux of water leaves the shuttle surfaces and the amount scattered back into the instruments is a function of the number of amblent scatterers which in the ram direction (low angle of attack) is maximum. Some sputtering of water vapor molecules from surfaces by $8-\mathrm{km} / \mathrm{sec}$ collisions by ambient particles is also likely, however.

Water is a major product of thruster firings and depending upon which thruster is being fired and on shuttle angle of attack, water vapor concentration is seen to rise by up to a factor of 10 during thruster firings. More details of the thruster firing events will be presented below. Given all of the uncertainties in measurement and interpretation, the column densities shown in Table 1 have been determined. The error bars on these values are uncertain, but a factor of plus or minus 10 cannot be ruled out. The wide range of values of the level of water vapor, particularly the great difference between STS -3 and -4 may be associated with the pre-launch environment. STS-4 suffered through a hale storm and subsequent rain. This combination of weather elements is believed to have led to STS-4 carrying some 2000 pounds of water to orbit. Waterproofing techniques have improved greatly and these early results are not typical of all flights. 
TABLE 1 (After Carignan and Miller) $\mathrm{H}_{2}{ }^{0}$ Contaminant Column Density $\left(\mathrm{cm}^{-2}\right)$

\begin{tabular}{lll}
\hline & MAX* & FINAL \\
\hline STS-2** & $2.0 \times 10^{13}$ & $2.7 \times 10^{12}$ \\
STS-3 & $1.5 \times 10^{11}$ & $4.0 \times 10^{10}$ \\
STS-4 & $3.2 \times 10^{13}$ & $1.0 \times 10^{12}$ \\
\hline
\end{tabular}

* Except for RCS firings and payload bay door closings.

**The STS-2 values are considered upper limits.

There is general agreement among the various measurements with regard to the nature of the contamination from thruster firings. Table $2 / 3 /$ shows densities before and during thruster firings. $\mathrm{H}_{2} \mathrm{O}$ increases by about $8, \mathrm{~N}_{2}+\mathrm{CO}$ by 13 and $\mathrm{NO}$ by 20 . The results of Narcissi et a1 /2/ and Miller / // agree well with these figures except for No. This difference in measurement is not explained and may be important in understanding the shuttle glow.

TABLE 2 (After Wulf and vonZahn) Neutral Gas Density (Number Densities per $\mathrm{m}^{3}$ ) and Composition of the Payload Atmosphere. Without and During Vernier Engine Firings

\begin{tabular}{|c|c|c|c|}
\hline $\begin{array}{c}\text { Mass } \\
\text { Numbers } \\
\text { amu }\end{array}$ & Constituents & $\begin{array}{l}\text { Without } \\
\text { Vernier } \\
\text { Firings } \\
\text { x } 1014\end{array}$ & $\begin{array}{l}\text { During } \\
\text { Vernier } \\
\text { Firings } \\
\text { x } 1015\end{array}$ \\
\hline 18 & $\mathrm{H}_{2} \mathrm{O}$ & 1.8 & 1.5 \\
\hline 28 & $\mathrm{~N}_{2} \mathrm{O}+\mathrm{CO}+$ traces & 1.8 & 2.3 \\
\hline 30 & NO + traces & 0.5 & 1.1 \\
\hline 32 & $0_{2}$ & 0.9 & 0.45 \\
\hline 44 & $\mathrm{Co}_{2}+\mathrm{N}_{2} \mathrm{O}$ & 1.4 & 0.65 \\
\hline \multirow[t]{2}{*}{ Rest } & traces & $<0.6$ & $<0.5$ \\
\hline & total & 7 & 6.5 \\
\hline
\end{tabular}

A significant difference between the IECM results and all the others is the presence in the IECM mass spectrometer of a large methane peak correlated with thruster firings. This has been attributed to catalytic conversion of partially oxidized MMH on zirconium oxide getters used to collimate the field of view of the spectrometer and so, in a sense, this methane peak may be regarded as an instrument artifact. The measurement has been attributed by some to a pressure dependent background of desorbents from the getters. There is no doubt about the correlation of these methane peaks with thruster firings so this observation may be a highly sensitive monitor of the flux of partially or unoxidized MMH. There is a literature $/ 5 /$ that shows a high content of partially oxidized fuel in pulsed reaction control systems. It is also possible that the NO peak in the Wulf and vonZahn $/ 3 /$ measurement is fractionated from the same source. Figure 2 shows an IECM plot of observed $\mathrm{H}_{2} \mathrm{O}$ and methane during a thruster firing. Also shown is a table of incremental composition values in good agreement with the ratios taken from Wulf and vonZahn /3/ except, as noted, for No. 


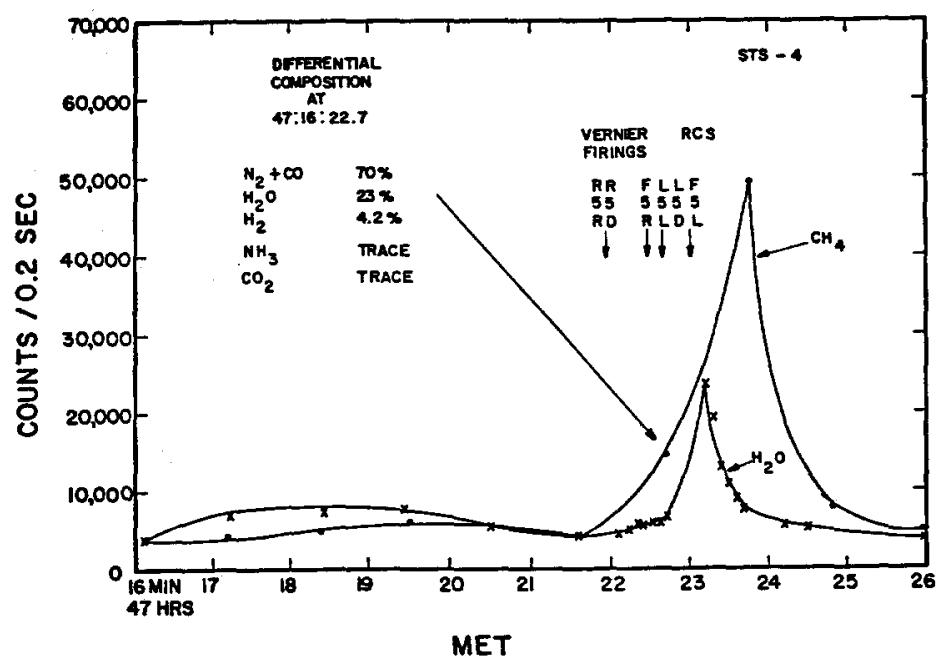

Fig. 2. The profile of methane and water count rates during a thruster firing event. The differential composition at one interval during the even is tabulated.

Wulf and vonzahn /3/ further observe that the forward thrusters have little or no gaseous signature at the spectrometer and that the Orbital Máneuvering System (OMS) firings produce only about the same level of contamination as do the aft thrusters even though the effluent is some 460 times greater. They theorize that both of these observations can be explained by the fact that the aft thruster plumes upward, downward and sideward, interact with the stabilizer, alleron and wings respectively while both the OMS and forward thruster effluent is expelled into space. The associated scattering off shuttle surfaces would, almost certainly, greatly increase the flux of contaminants into the payload bay. The results of the IECM are consistent with this interpretation although a detailed analysis of the correlation has not been performed.

On STS-4, the IECM was grappled by the Remote Manuvering System and moved out and oriented to look back at the shuttle bay and wings. The measurement of water during this period is shown in Figure 3. The ratio of outbound flux to inbound flux is about 50, a value consistent with the scattering model used given the ambient density at $305-\mathrm{km}$, the altitude of Columbia during this measurement. The variation with distance from the shuttle and lateral position 1s observable but not great suggesting a distributed source of flux, probably filling the field of view of the instrument. The arrows indicate offscale readings associated with thruster firings.

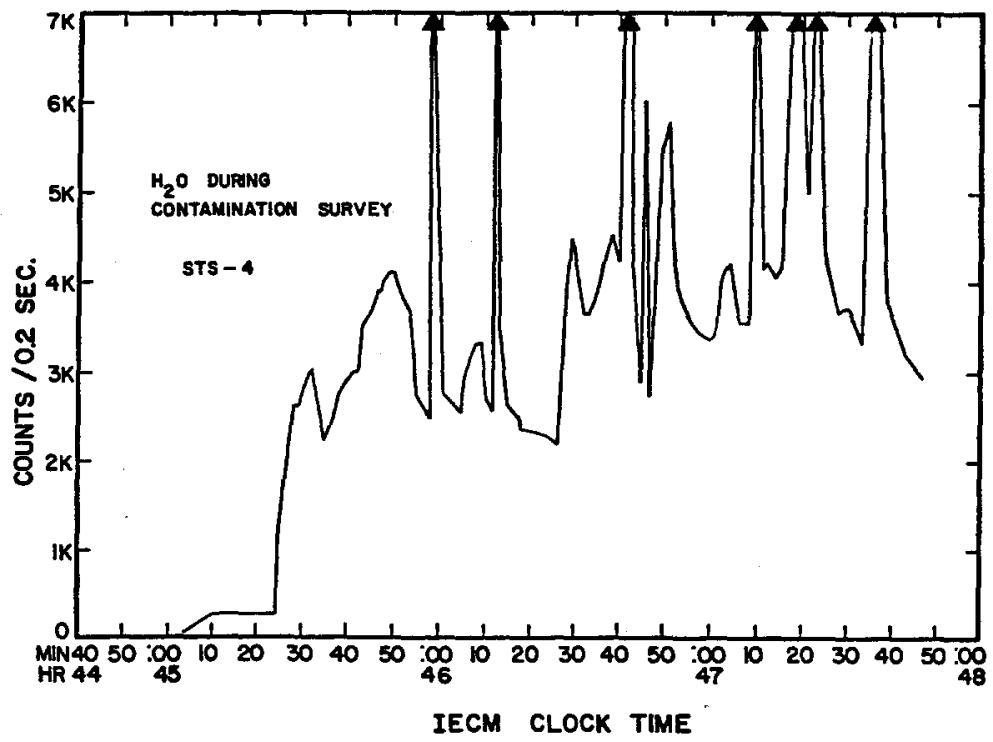

Fig. 3. A plot of mass 18 counts per 0.2 seconds while the mass spectrometer is on the RMS looking inward. The off-scale arrows correspond to thruster firings. 
Fifteen different viewing geometries were achieved during the survey. Nine of these are illustrated in Figures 4 and 5. The nominal field of view of the inlet is shaded in one position of each Figure; in all cases shown, the IECM is located on the center line of the $Y$ axis. The water vapor measurement, as a function of position number, is shown in Figure 6 . The maxima at positions 9 and 18 occur when viewing the aft payload bay.

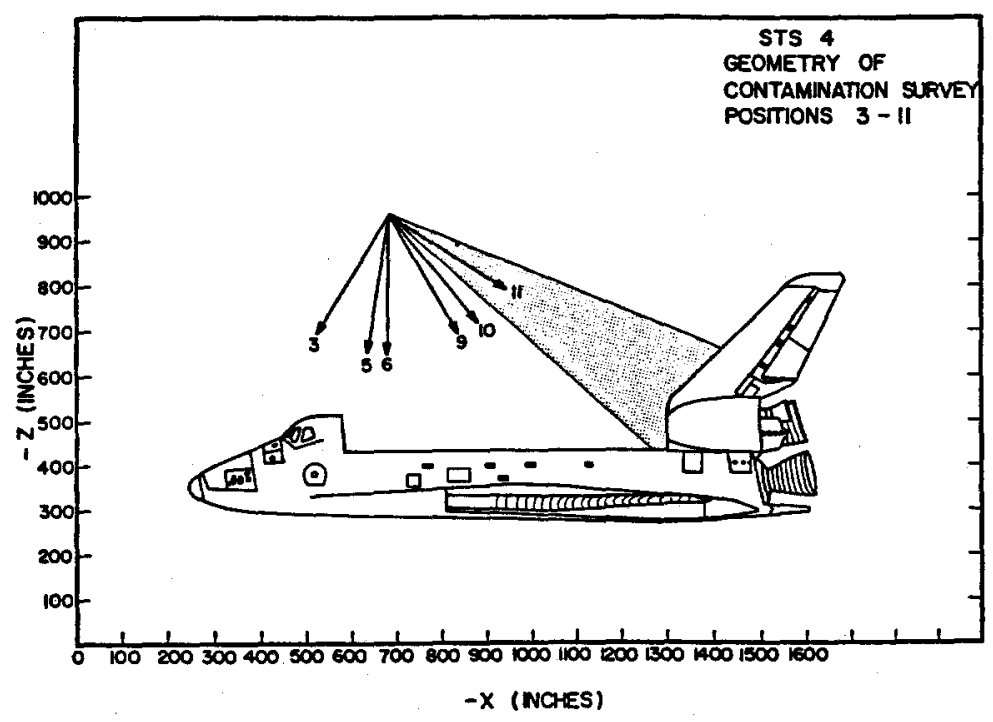

Fig. 4. A sketch showing the location of the mass spectrometer orifice and pointing vector during the contamination survey for data points 3 , $5,6,9,10$, and 11 .

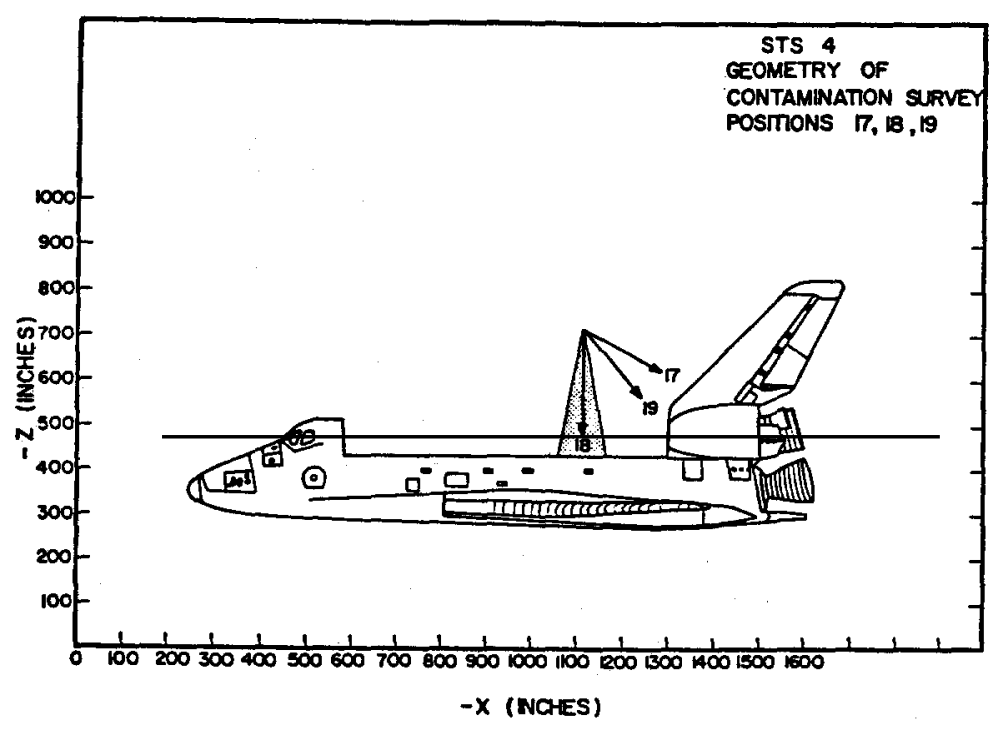

Fig. 5. Equivalent to Figure 4 for positions 17,18 , and 19. 


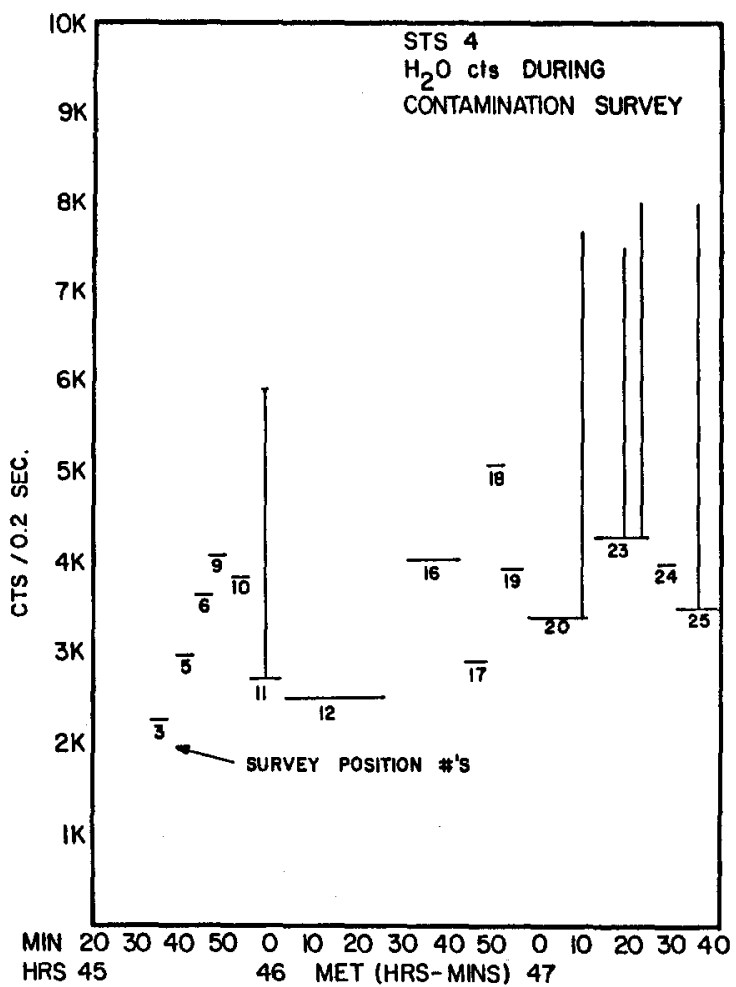

Fig. 6. The average values of the hass 18 counts for each position during the survey. The vertical lines indicate values observed during thruster firings at the associated position.

Helium has been a major contaminant on some shuttle flights. Figure 7 is a plot of helium count during the survey. The distribution is similiar to that for water but the peak value is much greater. Freons have a very characteristic mass spectrometric signature and the Freon-21 signature was unambiguously detected on STS-4. One of the spectral peaks, mass 67 , is plotted in Figure 8. The peaks at positions 11 and 17 seem to localize the source of the leak In the vicinity of the aft bulkhead and tall root. With the exception of Freons, concentrations of contaminants above 50 amu has been observed to be low on all flights.

Periodically during several shuttle flights the bay doors have been closed or partially closed with a mass spectrometer continuing its measurements inside the payload bay. A plot of the gaseous environment versus time from a door closing on STS-3 is shown in Figure 9. $\mathrm{N}_{2}$ and helium rise quickly to partial pressures in the $10^{-6}$ torr region and argon to about $10^{-7}$ torr. Water and methane rise more slowly so that at about 30 minutes after door closeIng the inside pressure is at about $10^{-5}$ torr with the indicated partial pressures. It is not known whether or not the payload bay before first opening has a similiar environment. 


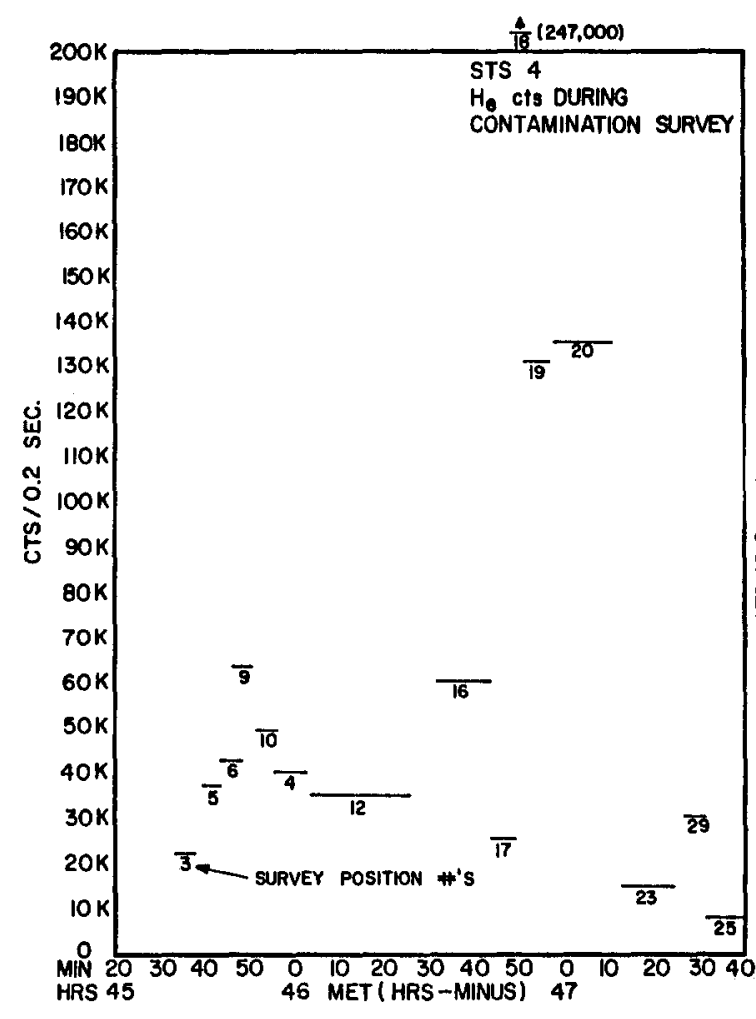

Fig. 7. Equivalent to Figure 6 for helium counts at mass 4 .

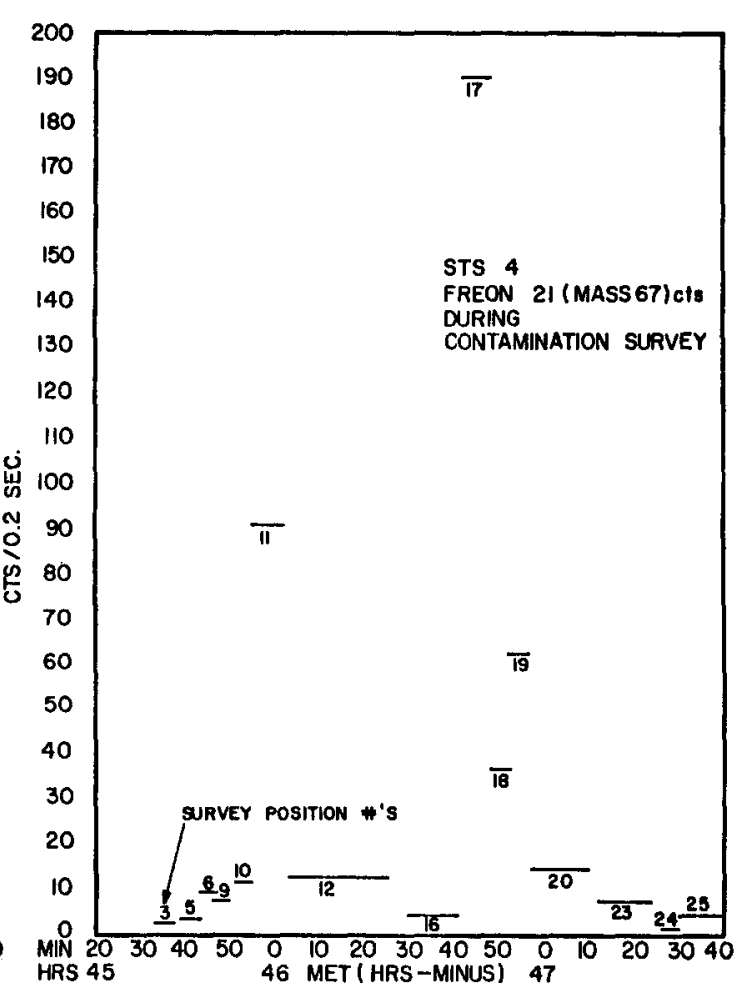

Fig. 8. Equivalent to Figure 6 for mass 67 counts interpreted as Freon-21.

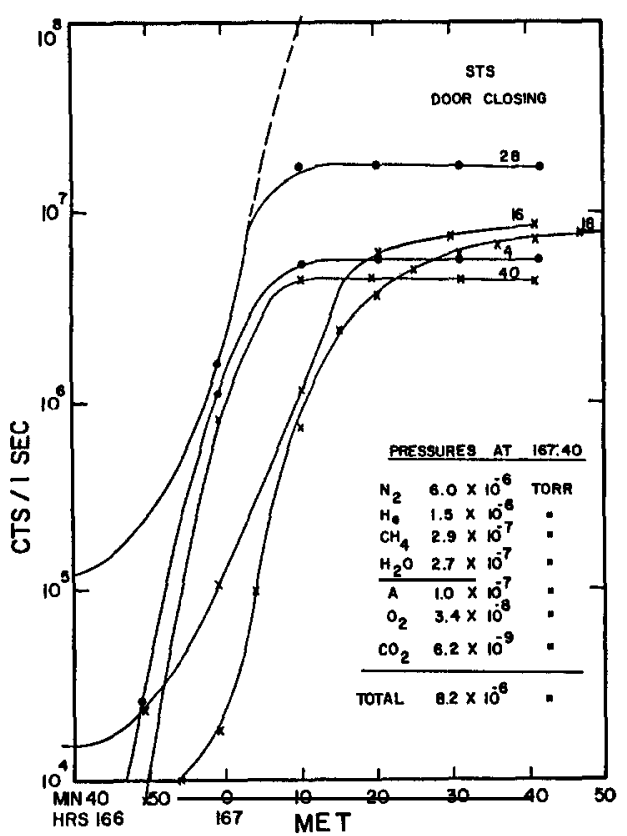

Fig. 9. Count rates for the principal constituents during a door closing event. The partial pressures near the end of the event are tabulated. 


\section{CONCLUSIONS}

The gaseous environment around the shuttle has been characterized by several instruments flown on many shuttle flights. Measurements have led to the following assessment:

-- The major contaminant is water vapor. It is highly varfable during a flight and from flight to flight, and the overall level decreases slowly during the course of a flight. Water dumps are not a strong source of contamination but the rear thrusters are.

- The rear thrusters are a major transitory source of water, $\mathrm{N}_{2}$ and/or $\mathrm{C} 0$ and possibly wo or some molecule that fractionates in the mass spectrometer to No.

--Effluent fluxes are scattered from the atmosphere into instrument faces. Angle of attack is thus an important variable in the flux levels.

--Instruments can be major sources of payload bay contamination. Liquid helium cooled systems, for example, create a significant helium contamination.

An awareness of the variable nature of the shuttle induced gaseous environment allows timeline planning by experimenters to avold operation or exposure during pertods of higher levels of contamination. (e.g., early mission times, intervals of major engine or thruster firings, high temperature aititudes). Contamination avoidance also demands mission and payload compatibility so that operational requirements can be met without conflicting restrictions on activities that produce high levels of contamination.

\section{REFERENCES}

1. E.R. Miller, STS-2, $-3,-4$ Induced environment contamination monitor (IECM) Summary Report, NASA Tech. Memo., (Feb., 1983)

2. R.E. Narcissi, E. Trzcinski, G. Fredrico, L. Wlodyka, and D. Delorey, The gaseous and plasma environment around space shuttle, AIAA Pap., 83-2659, (1983)

3. E. Wulf and U. vonZahn, The shuttle environment: Effects of thruster firings on gas density and composition in the payload bay, J. Geophys. Res. 91, 3270 (1986)

4. J.M. Grebowsky, M.W. Pharo III, H.A. Taylor, Jr., and I.J. Eberstein, Measured therma1 ion environment of STS-3, AIAA Pap., 83-2597, (1983)

5. C.-K. Liu and A.P.M. Glassford, Contamination effect of MMH/ $\mathrm{N}_{2} \mathrm{O}_{4}$ rocket plume product deposit, AIAA Pap., 81-4212, (1981) 